\title{
ATUALIDADES DO "ROCHEDO" FREUDIANO: 0 "PRIMEIRO HOMEM GRÁVIDO"
}

Vincent Bourseul e Laurie Laufer

\author{
Vincent Bourseul \\ Psicanalista, \\ professor substituto \\ do Laboratório \\ Interdisciplinares \\ Narrativas, Culturas \\ e Sociedades \\ (Lirces EA3159) da \\ Universidade Nice \\ Sophia-Antipolis.
}

Laurie Laufer

Psicanalista, professora de Psicopatologia do Centro de Pesquisa em Psicanálise, Medicina e Sociedade (CRPMS EA 3522) da Unidade F e Pesquisa em Estudos Psicanalíticos da Universidade Paris Diderot-Paris 7.

Tradução Fabiana Campos Baptista Doutora em Psicopatologia e Psicanálise (Universidade Paris Diderot). Mestre em Psicanálise (Universidade Paris 8). Mestre em Psicologia (UFMG). Professora adjunta do curso de Psicologia do UNI-BH.
RESUMO: A partir do caso, divulgado pela mídia, de Thomas Beatie, o "primeiro homem grávido", revisitamos interrogações freudianas sobre o "fator" da diferença sexual e as dificuldades encontradas pela análise no ponto de limite do "rochedo" identificado por Freud. Detectamos, neste caso, um possível eco da "recusa do feminino", em particular na produção da expressão "homem grávido”, grafado com "o". Concomitantemente, o "rochedo" se revela em sua função de dobradiça entre a reatualização dos conflitos psíquicos do passado, o tratamento dado a isso e a abertura ética promovida por Freud de um posicionamento do sujeito face à experiência da diferença sexual, tornada acessível pela análise.

Palavras-chave: Complexo de castração, reprodução assistida, transexualismo, identidade sexual, paternidade.

ABSTRACT: Current issues on the Freudian 'rock': 'the first pregnant man'. From Thomas Beatie's story, reported by the media as the "first pregnant man", we revisit some Freudian questions about the "factor" of the sexual difference and the difficulties found by psychoanalysis at the limit point of the "rock", identified by Freud. We have detected a possible echo of the "refusal of the feminine", particularly in the French spelling of the expression "pregnant". Concurrently, the "rock" is revealed in its hinge function between the updating of past psychic conflicts, their treatment and the ethical openness promoted by Freud of a positioning of the subject according to the experience of sexual difference, made accessible through psychoanalysis.

Keywords: Castration complex, assisted reproduction, transsexualism, sexual identity, paternity.

DOI - http://dx.doi.org/10.1590/S1516-14982016000100001 


\section{O "HOMEM GRÁVIDO" ONTEM E HOJE}

Em 2008, o jornal americano The Avocate, ${ }^{1}$ assim como várias outras mídias pelo mundo afora nos informava, em sua edição de 14 de março, o nascimento próximo de uma criança cuja mãe era um homem. O "primeiro homem grávido", nos disseram sobre Thomas Beatie, transexual americano com então 34 anos.

Entretanto, ele não era o primeiro homem a ter dado nascimento, a ter gerado ou a ter parido uma criança... existiram outros antes dele. Outros homens transexuais que deram corpo ao que antes só existia como mito. O mito mais célebre é, sem dúvida, o de Adão, de quem Deus começa retirando uma costela para transformá-la em Eva. Em todo caso, foi assim até o século XVI, quando Eva surgirá do corpo de Adão sem vir da extração de uma costela. Mas, nesse caso, Adão não é o único.

Roberto Zaperri, escritor e historiador que consagrou, em 1979, um estudo muito interessante sobre esta questão, assinala a presença de um mito do Homem grávido (ZAPERRI, 1979) na tradição cristã, nas Mil e uma noites, na Antiguidade e nos dois casamentos do Imperador Nero, que teria ficado grávido de um de seus amantes. A análise é especialmente instrutiva quando ele coloca em evidência o caráter político dessas variações em torno do "homem grávido", que, de seu ponto de vista, se separam em duas grandes categorias opostas: a primeira, que é a da superioridade do homem sobre a mulher e a segunda, correspondendo à autoridade do senhor ou do homem da Igreja sobre seu camponês ou fiel. Algo importante para se levar em consideração é a oposição entre horizontalidade e verticalidade. Com efeito, na maior parte das lendas, a ameaça de uma gravidez do homem teria como objetivo fazer respeitar a necessária superioridade do homem sobre a mulher no momento do coito.

Esta verticalidade ressoa inclusive com o que Thomas Laqueur nos ensina em La fabrique du sexe (LAQUEUR, 1992) sobre esta época não tão longínqua, em que só existia um sexo, um sexo que não designava o ser macho, já que ele era o único e não tinha nenhuma necessidade desta distinção. Isto se organizava também em uma relação vertical, em que os órgãos visíveis da mulher, versão reduzida ou complementar do sexo do homem de acordo com as épocas, se situavam, então, acima. Foi preciso esperar o século XVIII para que o sexo fêmea aparecesse, aparição que Laqueur nos leva a compreender como sendo uma operação de segurança masculina. Apesar de dar uma existência específica aos órgãos das mulheres, são os órgãos dos homens que continuam, desde então, a assegurar sua superioridade, em uma época em que se temia que o saber sexual fosse capaz de colocar em questão a hegemonia masculina. Depois disso, fala-se em dois sexos, mas por quanto tempo?

\footnotetext{
1 “Labor of love, Is society ready for this pregnant husband?" The avocate, 14 mars 2008.
} 
Mas, então, por que nós dissemos que Thomas Beatie seria o primeiro? E por que dissemos "grávido" e não "grávida”? O que esta formulação pode nos ensinar sobre o que a história de Thomas Beatie produz ou revela com relação a saberes sexuais e seus efeitos? O corpo-trans carrega consigo a marca da "recusa do feminino"? Ou será que são nos efeitos do corpo-trans, tal como ele é acolhido e vivenciado pelos outros corpos, que se manifesta esta "recusa”? Talvez a história de Thomas Beatie faça ressoar em cada um de nós as lembranças fugidias da experiência da diferença sexual, cuja "recusa do feminino" testemunha uma forma de resolução da diferença sexual. Thomas Beatie questionará, em cada um de nós, a possibilidade de uma outra "solução”, uma outra via possível à experiência do "rochedo".

\section{THOMAS BEATIE, "GRÁVIDO" COM "O"}

Thomas Beatie é um homem (FtM) 2 americano nescido em 1974 no Havaí, com o nome de Tracy (BEATIE, 2008). Ele se tornou homem depois de um tratamento hormonal e de uma mastectomia. E não teve, entretanto, recurso para uma "reatribuição sexual cirúrgica”, tal como uma faloplastia ou metoidioplastia. Como consequência, conservou seus órgãos reprodutores: útero e ovários. Casado com Nancy, sua esposa, Thomas investiu em um procedimento de reprodução assistida. O casal desejava ter filhos desde o começo de sua história, mas Nancy é estéril. Thomas Beatie dá à luz, pela “via natural”, a uma primeira criança, em 29 de junho de 2008, e depois a outras duas crianças, em 9 de junho de 2009 e a última em 25 de julho de 2010.

Sua história e a de sua família foram muito mediatizadas no mundo todo, principalmente por iniciativa de Thomas, que desejava que sua aventura se tornasse conhecida. Ele publicou um livro, no qual conta seu percurso (BEATIE, 2008). Dezenas de reportagens e documentários retrataram esta família a princípio atípica, mas que se revela, pouco a pouco, bem comum. Com efeito, é interessante notar nestes arquivos audiovisuais, a que ponto o imaginário proposto por Thomas e sua família é o de uma família americana comum. Todos os observadores concordam em dizer que a vontade de passar uma imagem de normalidade está, no momento da divulgação da história, no cerne das preocupações de Thomas.

“O primeiro homem grávido", disseram sobre Thomas Beatie, e outros, antes e depois dele, esquecendo-se, um pouco rápido demais, de que Thomas Beatie propôs outra formulação que não foi ouvida nem retida, ao se apresentar como o "marido grávido". E isso é algo que devemos ter em mente para o que está por vir. Destacamos que “homem” é escrito como “h” minúsculo, "grávido” sofre

\footnotetext{
${ }^{2}$ Do inglês FtM Female to Male. Traduz-se por "de mulher para homem”.
} 
um acordo em relação ao gênero gramatical — com o "o” — fazendo referência ao nome masculino "homem” que ele qualifica. Lendo e dizendo, este enunciado parece dar corpo e sentido a uma realidade pouco comum, quase impossível.

Formulando sem dúvida bem rapidamente a expressão "o primeiro homem grávido”, o enunciado atropela e camufla o que estava explícito em um desvendamento brutal, um desvendamento do sexual; a expressão é um recurso provisório, mas, ainda assim, eficaz. Trata, através de uma formalização simbólica, o que do Real, do real do sexo, encontra-se ao mesmo tempo recoberto, ou talvez desmentido. Pois, afinal, por que não dizer “o primeiro homem grávida”? Por que fazer este acordo gramatical, no gênero masculino, tão rápido, de forma tão facilmente consentida? O enunciando celebra um ponto de verdade da história de Thomas Beatie, respeitando o que seria aqui considerado como sendo sua identidade sexual, a saber, que ele é um homem e que, como consequência disso, convém masculinizar ou desfeminizar a gravidez do corpo a partir do qual ele fala? Colocar o "o" no lugar do "a” se articula à boa forma de dizer de acordo com as conveniências, para tomar o sentido de seu caso pessoal? Ou esta operação de concordância realiza ainda outra coisa?

Temos a hipótese de que esta reescritura de grávida para grávido, com “o”, seja uma desfeminização do termo que tende a manter o homem com "h" minúsculo em seu lugar no discurso, o que parece sobreviver a uma "ordem simbólica". Renovando desta forma a ortografia da palavra, pensamos, neste enunciado, no homem que precede a esta escrita, e é a ele que nos ajustamos ao concordar o qualificativo "o" com o nome ao qual ele se reporta. Não é certo que vamos dar conta, nesta formulação, de uma parte da verdade que Thomas Beatie encarna e que merece ser destacada por uma gramática menos normativa e com ortografias menos floreadas. Uma verdade que vem e que nos ensina, nos faz retornar sob uma nova figura do parentesco, alguma coisa que foi anteriormente perdida ou abandonada. Uma verdade-rejeição que é um recalcamento, que pode ser sinal de uma exclusão, vinda de fora, de um saber insuportável vindo de dentro, inquietante ou louco. Não diríamos que um "homem grávido é alucinante!”?

Mas compreendemos: o que é este "o" que faz retorno, ou que nos aparece quando "o grávido" concorda gramaticalmente com o homem como se fosse desde sempre algo dele, como se fosse dele, como se, de repente, o homem carregasse a criança e a parisse, como se isso não fosse nada? É espantoso: há um risco de perder o essencial e concordar com o homem da gramática e com suas regras. Este homem capaz de engravidar parece a ponto de se deixar enganar por uma construção teórica infantil capaz de garantir um estado de indistinção sexual, que a experiência da diferença sexual vem desmontar, deixando aparecer os efeitos da bissexualidade psíquica. E olhando de perto, estar "grávida” não é tão simples assim, etimologicamente falando. Vem do verbo “cercar” e significa 
estar cercado por alguma coisa, fazer círculo. ${ }^{3}$ É o feto que merece ser dito "grávido", pois ele está cercado pela placenta, pelo ventre da mãe, etc... Mas dissemos também "ficar grávida" — como ficar apaixonado ou ficar doente que se aproxima mais do fato de ter se tornado "uma grávida"/"uma cercada" pela gravidez, uma "grávida/cercada" que acolhe o feto.

A expressão corrente literalmente rejeitou o artigo definido "uma" para virar simplesmente "estar grávida”. Esta pode ser, talvez, a rejeição da verdade que acabamos de evocar mais acima. "Estar grávida” ou "estar uma grávida” do fato devido ao estado psicológico da gravidez parece se sustentar na possibilidade, em primeiro lugar, e menos diretamente no que a expressão corrente e seu acordo gramatical deixa entender, a saber, que isso seria assunto de mulher, enquanto que, na verdade, é um assunto de gravidez. Se o uso corrente realizou este acordo gramatical, não é sem fundamento. Foi preciso, sem dúvida, sustentar a gravidez com a mulher, sustentar para a mulher a possibilidade de uma gravidez. Sustentar a mulher em relação ao homem não engana a gramática, ela mesma tornou-se cúmplice de um jogo de engano sutil com finalidades inconscientes. É que uma ordem deve se sustentar; poderíamos dizer que é uma ordem simbólica, mesmo se ela for imaginária. Concordar com o masculino pode fazer com que não nos demos conta de que a "grávida/cercada” é, primeiramente, um lugar, um lugar do corpo, bem antes e bem depois de ser um qualitativo ou um estado.

A linguagem nos permite, então, reduzir a coisa, o lugar da "grávida/cercada" a um estado, uma qualidade, tentando fazer calar o impossível da gravidez para fazê-la passar por alguma efêmera, que não dura — como o amor ou a doença. Com um homem grávido, prolonga-se o arranjo estrutural, linguajar da mulher no discurso, e é o corpo vazio, impossível e impensável da mulher, o real do sexo que continua a ser rejeitado sem que seja possível se desfazer dele totalmente, pois ele volta ou persiste. A gravidez é uma ocasião de fazer sustentar o lugar impensável como um enigma, e fornecer, sem dúvida, um pequeno conforto pela ilusão de um domínio, de uma organização.

O subterfúgio linguajeiro "grávida” que acabamos de percorrer apresenta-se, sob esse esclarecimento, como um vestígio, como um lugar de celebração paralela ao lugar do corpo da mulher santuarizada. O enunciado "o primeiro homem grávido" carrega, então, a marca desta operação inconsciente de afastamento, de dissimulação de uma verdade rejeitada.

\footnotetext{
${ }^{3}$ Em francês, "enceinte" é traduzido como "grávida". O autor mostra que, etimologicamente, a palavra "enceinte" significa "estar cercado por algo". Entretanto, o termo em português "grávida" não participa da mesma raiz etimológica que seu correspondente em francês. Gravidez vem do latim gravis, gravidus e significa pesado, carregado ou ainda "mulher em estado de gravidez". Outra diferença é que a língua portuguesa admite o uso da palavra no masculino - grávido - para se referir ao "que está em estado de gravidez" ou mesmo "útero grávido" (N. da T).
} 
Mas qual é essa verdade? Há outra hipótese. O "o" carrega nele o traço de um desejo contrariado e podemos considerar a seguinte tradução: "Ser uma mulher como um Homem", homem com "H" maiúsculo, como possível ilustração de um fantasma articulado à "recusa do feminino". Isso corresponde ao projeto de se ter uma criança de Thomas Beatie, que é um projeto de pai, homem e marido. Seu objetivo parece ser o de construir uma família bem diferente da sua. Sem dúvida, ela não poderia ter conhecido esse desenrolar se Thomas não tivesse conhecido Nancy e se apaixonado por ela, e a quem ele fez "doação de gestação", à ela e à sua família. "Ser mãe como um Homem” é, dentre outras coisas, ser mãe como um "bom pai de família", segundo a expressão corrente.

Na mediatização dessa história, a questão do gênero se revela socialmente encarnada, trata-se de papéis parentais tradicionais que são valorizados, para além do sexo, e que ficam entregues ao corpo ou àquilo que é da anatomia e de suas funções naturais. Assim, certo transtorno é evitado. O véu de normalidade do projeto de Thomas e Nancy foi encorajado pela leitura dos acontecimentos, pois, no fundo, se toda a imprensa ${ }^{4}$ cobriu o caso com muita benevolência, foi sem dúvida porque os valores familiares e a ideia de uma América serena com ela mesma foram preservados e, através desses elementos, uma paz relativa sobre as questões sexuais de fundo que puderam continuar não ditas e inconscientes também o foram. Nancy amamentou seus filhos, Thomas "pariu como marido" e não como homem, mas como homem responsável da família. Não foi o que, inclusive, disse Thomas dele mesmo quando se expressou dizendo: "marido grávido", "Meu nome é Thomas Beatie e tenho uma família", "Parir como marido", "my own surrogate”... Eis quem normatisa a família: os pais e as crianças. Thomas Beatie, como transexual, representa um transtorno no gênero, mas, como homem grávido com "o", parece menos perturbador com a ajuda da língua, dos nossos acordos gramaticais e com a ajuda do direito e da Lei. Com o “o”, o "feminino" problemático é dominado para assegurar a calma necessária ao aparelho psíquico.

\section{A "RECUSA DO FEMININO"?}

Retomemos as questões suscitadas a partir do caso Thomas Beatie, e notadamente esta, bastante representativa: o corpo-trans é a marca da "recusa do feminino"? Ou, como sugerimos antes, não é o efeito do corpo-trans como receptor que pode suscitar uma reação em relação à "recusa do feminino", dando lugar, por exemplo, à troca do "a" pelo "o" para proteger-se?

\footnotetext{
${ }^{4}$ Documentário Pregnant man, realizado pelo canal de televisão Discovery Real Time, divulgado em 6 de junho de 2009.
} 
O que é a "recusa do feminino"? Freud formulou a "recusa do feminino" em 1937, no fim de sua vida, no texto Análise terminável e interminável (FREUD, 1937). Aqui, Freud traduz o que ele nomeia também de o "rochedo de origem" contra o qual fracassam todos os esforços terapêuticos. Notemos que esta proposição constitui um avanço teórico, como salienta Jacqueline Schaeffer (SCHAEFFER, 1997), avanço no qual Freud posiciona a força da pulsão — em sua dimensão quantitativa - como um problema "originário" responsável por esse combate com o eu. Fazendo isso, ele precisa e articula sua reflexão para transportar, de certa maneira, essa dualidade combativa para a histórica bissexualidade psíquica dos seres, bissexualidade que é a sede das tensões internas originárias. Dessa reflexão, Freud traduz a "recusa do feminino" como sendo exemplar da reação dos seres sexuados diante de certo "fator", e Schaeffer tem razão em ressaltar não ser tanto a "recusa do feminino" o problema, mas o próprio "feminino". Esse texto é, portanto, a ocasião, para Freud, de voltar a uma consideração renovada de sua abordagem, a partir da bissexualidade psíquica dos dois sexos e da recusa do feminino nos dois sexos, para avançar sobre os obstáculos encontrados durante a análise.

Tomemos o texto em detalhes. Segundo nossa leitura, Freud nos conduz a um ponto relacionado aos efeitos da pulsão na edificação do corpo como produção psíquica. Quando ele escreve:

"A força constitucional da pulsão e uma alteração desfavorável do eu, adquirida em sua luta defensiva, no sentido de ele ser deslocado e restringido, são os fatores prejudiciais à eficácia da análise e que podem tornar interminável sua duração. (...) deveriam perguntar quais obstáculos se colocam no caminho dela." (FREUD, 1937)

e situa a possibilidade de uma dificuldade do processo terapêutico no próprio lugar da constituição do psiquismo. Os elementos que fazem obstáculo são, então, de origem, ainda que o recalcamento originário dilua seus rastros, ainda que eles reapareçam sob os traços de um "rochedo" reencontrado ao longo da cura, quando ele é, no fundo, redescoberto. O que nos encoraja a ressaltar do texto freudiano é como esse "rochedo", que a análise reativa à sua maneira, se edifica sobre os vestígios de uma construção psíquica sem precedentes. Isso nos permite sublinhar que, se a psicanálise não segue um objetivo predeterminado a ser atingido, isso não significa que ela não siga certos fins.

Mais tarde, ele considera a transferência negativa como sendo a domesticação necessária da reivindicação pulsional... E, de passagem, interroga o fim, não do processo, mas do objetivo da análise: "Não é reivindicação de nossa teoria que a análise leva a um estado que não surge espontaneamente no eu e que esse estado constitui a diferença entre uma pessoa analisada e outra que não o foi?" 
(FREUD, 1937). É que, neste caminho, a análise visa o estabelecimento de "novos diques", de novos recalcamentos capazes de reduzir a influência pulsional por “correção après-coup do processo de recalcamento originário, que põe fim à força excessiva do fator quantitativo" (idem). Infelizmente, os resultados parecem, com frequência, parciais aos olhos de Freud, e pouco a pouco emerge a ideia de outros motivos que seriam responsáveis por essas insuficiências ou por essas conquistas terapêuticas inacessíveis. Em seguida, ele desenvolve o dualismo pulsional, em que a tensão, o combate e a rivalidade aparecem como qualidades que emergem a partir do fator quantitativo. Freud postula novamente, como no caso da pulsão de morte ligada à pulsão de vida, a possibilidade de um conflito de orientação da força pulsional de acordo com trajetos de ação concorrentes. Ele se apoia, então, na questão da bissexualidade constitutiva e da heterossexualidade vivenciada — como escolha de objeto — que não podem coabitar em um mesmo indivíduo sem criar uma tensão interna. Encorajado pela conferência de Ferenczi de 1928 sobre La terminaison des analyses (FERENCZI, 1928), Freud escreve: “Não se pode discutir sobre se os analistas, com suas próprias personalidades, não estiveram invariavelmente à altura do padrão de normalidade psíquica para o qual desejam educar seus pacientes” (FREUD, 1937). Afirmando isso, Freud deixa entender que os obstáculos à análise são inerentes à psicanálise e que os próprios psicanalistas são um dos lugares desta resistência. Anuncia-se aqui, em nossa opinião, as premissas do futuro desenvolvimento sobre o rochedo.

Na última parte do desenvolvimento do texto, Freud avança sobre a bissexualidade psíquica e a "recusa do feminino" nos dois sexos, e conclui: “Isso é provavelmente verdadeiro, já que, para o campo psíquico, o campo biológico desempenha realmente o papel de rocha subjacente. O repúdio da feminilidade pode ser nada mais do que um fato biológico, uma parte do grande enigma da sexualidade. Seria difícil dizer se e quando temos êxito em dominar esse fator num tratamento analítico. Só podemos nos consolar com a certeza de que demos à pessoa analisada todo o incentivo possível para reexaminar e alterar sua atitude para com ele" (FREUD, 1937). Essa passagem chama nossa atenção, e é a partir de sua leitura e interpretação que buscamos propor uma visão dessa "recusa do feminino", à luz do caso de Thomas Beatie, que representa, talvez, uma "solução" ao "rochedo". A conclusão do texto é surpreendente, pois é, ao mesmo tempo, o reconhecimento de uma impossibilidade do trabalho analítico em conduzir o analisando para além de certo ponto, e também a recomendação de que o analista esteja apto a oferecer ao analisando a possibilidade de conseguir levar sua análise adiante e de se situar nela em seu próprio nome. Thomas Beatie encarna, por seus singulares arranjos, uma ultrapassagem, em ato, do "rochedo"? Ou ele confirma, pelos efeitos suscitados nos outros, o ponto de limite? 
Esse "rochedo" poderia, então, ser considerado uma via sem saída, dando à análise sua infinitude? Não devemos considerar que o "rochedo" é, ao mesmo tempo, intransponível e, no entanto, superável? De fato, ele é a marca de um inacessível do sujeito, cujas coordenadas de sua configuração histórica podem, pela análise, ser ouvidas a ponto de permitir ao próprio paciente vislumbrar uma possível mudança de posição em relação a esse fator e de dispor de um novo grau relativo de liberdade.

Não seria essa uma definição possível de término de uma psicanálise? O "rochedo" pode perfeitamente ser visto também como o rejeito último do inanalisável do sujeito — o umbigo final — , em torno do qual ou a partir do qual se ativa seu desejo de verdade, seu desejo e a capacidade de reabertura do processo de elaboração. Não seria, ao final do trabalho analítico tal como pensa Freud, o retorno ao vestígio do primeiro apoio sobre esse movimento primeiro que, instaurando o recalcamento originário, permite, a partir do corpo e pela linguagem, a emergência do sujeito? Nessa perspectiva, o "rochedo” não seria a eclosão desse retorno impossível, perceptível somente por uma ou outra de suas partes, ou por uma de suas bordas? Não é isso que Thomas Beatie reivindica, na forma como ele se representa, como uma espécie de compilação do que foi antes dividido e separado? O "corpo-trans" não daria a ele uma forma e uma representação "real" a essas questões habitualmente mais obscuras e sem corpo? Estimamos que esse "corpo-trans" seja uma nova presença de questões mantidas em geral com discrição, sem forma e sem figura, que nossa modernidade torna visíveis.

Mas, então, por que falar de "feminino"? Por que este retorno ganha forma sob a marca da diferença sexual em particular, tendo o feminino como estandarte? Freud fala de qual feminino? Não se trata, talvez, de assinalar a necessidade de se tornar sujeito, de se criar a partir do corpo hospitaleiro que acolhe sua emergência (dele, mas também da mãe) por dentro, pela pulsão e pelos órgãos, e em sua superfície, pela linguagem e pela imagem do corpo?

O feminino não voltaria pelo fato de, no início da vida, toda pessoa ser marcada pela bissexualidade psíquica originária, mas sim porque, além disso, ele ocupa esta posição fundamentalmente feminina que lhe permite assumir uma passividade que é a condição da constituição do sujeito. O feminino do qual falamos não poderia, evidentemente, ficar restrito à "feminilidade" genital. Podemos pensar no trabalho realizado pelo eu nascente, "de introjeção de movimentos pulsionais intensos, mas que se tornaram toleráveis pelo lugar que ocupam na relação primitiva” (SCHAEFFER, 1997). É um feminino matricial, dos órgãos onde a pulsão se anima, que seria recusado a título de período originário que ele representa para cada ser, recusado pelos efeitos da análise, quando esta leva o analisando a esse ponto específico de sua história psíquica pessoal, e que suscita 
nele a rejeição de não poder ser reconhecido, sem convidá-lo a se livrar dele, a desviar o olhar e a recusar o que já foi, no passado, constituído pela negação: Verdrangung, Verneinung, Verleugnung... (RABINOVITCH, 2000)

Thomas Beatie é uma encarnação possível deste retorno alucinatório que leva, por reduzir o conflito psíquico, a situar a possibilidade da gravidez fora do homem, ou ainda, artrelá-la ao passado. A "recusa do feminino" provocada - e parcialmente encarnada - por Thomas Beatie seria, então, uma repetição, ou eco de um movimento de rejeição-negação fundador. Thomas Beatie representa essa "feminilidade" no paradoxo de ser mãe como um Homem. É aqui que se ativa a "recusa", no ponto do "rochedo" sublimado, ultrapassado e renovado por Thomas Beatie, como se conhecer sua história o fizesse vivenciar uma experiência cujos efeitos se aproximam aos do "rochedo" como efeito de análise.

Distinguimos, então, o "rochedo" biológico e a "feminilidade" que se liga a ele sob a pluma de Freud. Ele não é o todo do "feminino", ainda que faça ressoar seus traços psíquicos em uma atualização que interessa ao tratamento, mas que se manifesta também fora da dele. A retomada, por Freud, do argumento da bissexualidade constituinte é acompanhada do fato de que isso não poderia se dar de outra maneira. Assim, pode-se pensar que o "feminino" rejeitado pode ser escutado, fundamentalmente, na letra "a" trocada pela letra "o", símbolo do silêncio jogado nessa bissexualidade problemática e insistente.

Mais do que um ponto de limite que impede avançar para ir mais longe na análise, o "rochedo" é uma espécie de ponto de chegada, ou um ponto decisivo da análise, revelador, em todo caso, de certa progressão do trabalho cumprido. Quando a análise é levada até este ponto, não teremos entrado em territórios em que as palavras se perdem por vezes até não poderem mais sair de um corpo frente ao qual elas se desfazem? Não estamos, então, restritos a um trabalho de rememoração que, acolhendo o retorno de movimentos vindos de um tempo anterior à linguagem, pré-genital, daria a eles figuras humanas? O psiquismo não teria, então, a função, até onde ele puder, de fazer vir à linguagem este for intime com o qual ele toca o corpo no qual se origina? Essa "recusa do feminino" não seria testemunho de uma história sem palavras, que, por ser convocada no momento presente analítico, captura o analisando e o condena a recusar o que, no entanto, originariamente, se realizou para fazê-lo existir, mas cuja possibilidade de um retorno causa temor? É que sua qualidade "originária” obriga o sujeito a recusá-lo repetidamente, sem nem poder se lembrar dele, pois este recalcamento (originário), que retorna com frequência, nunca é esperado. Não seria isso o que se produz na troca do "a" de "grávida” pelo "o" de "grávido", manobra eficaz, mas nem definitiva nem completa, assim como Thomas Beatie vem nos lembrar?

Thomas Beatie realiza o "rochedo", desviando-se parcialmente dele, tornando-o transponível em sua efetividade biológica, e reatualizando seu caráter intrans- 
ponível, pois gerador de arranjos de linguagem que tendem a circunscrevê-lo novamente. Ele prova ainda que nenhuma das transformações técnicas ou corporais livra quem quer quer seja dos processos psíquicos inconscientes necessários à sua integração psíquica. Se suas leis não se transformam na mesma medida em que elas se atualizam, isso nos oferece, apesar de tudo, novas perspectivas terapêuticas no presente de suas atualidades psíquicas.

\section{PARA CONCLUIR}

Freud escreve ao final de sua conclusão: "modificar a posição em relação ao fator". Certamente, não há esperança em eliminar o fator, mas são as produções psíquicas que resultaram disso é que podem hoje, ao final da análise, ser reconsideradas, um espaço se abre. Esse fator, que mostra que a diferença sexual sustenta e permite a emergência do próprio sujeito pelo reconhecimento da diferença sexual por sua conta própria e pelos outros, cumpriu um papel essencial nesta obra necessária. Ele pode, a partir de então, no momento da análise, ser visto de outra maneira pelo analisando.

Assim, vemos emergir a possibilidade de um novo posicionamento ético do sujeito em relação a esse fator - compreendido como a diferença sexual originária onde o sujeito se diferencia sexualmente para existir como um; surge, então, a possibilidade de reintegrá-lo em uma elaboração analítica capaz de dar-lhe uma versão diferente daquela em que encontramos os traços em uma análise tomada como geradora mais de divisão do que de união. Pela análise, é dada ao ser sexual a possibilidade de pensar sua constituição histórica pessoal a partir e dentro da diferença sexual, e nutrir, através dela, sua ética pessoal.

O "gênero" que os pacientes empregam às vezes, não poderia, na clínica, ser trabalhado nessa perspectiva terapêutica e ética psicanalítica? A história de Thomas Beatie nos faz vivenciar a experiência de uma operação de "recusa do feminino" em grande escala, que situamos particularmente em vista dos elementos que acabamos de percorrer, na recepção de sua história pelo público e pela mídia. A correção ortográfica de "grávida" com "o" é uma forma de retificação sexual na linguagem.

A história de Thomas Beatie nos leva a esse "fator" identificado por Freud e ao interesse pelo "rochedo", pois torna possível ao sujeito revisar sua posição, e é isso que a análise permite interrogar e renovar, como Freud acreditava. A partir de sua "recusa", o "feminino" pode ser entendido como o suporte de uma criação moderna de um novo gênero que se situa na mesma continuidade psíquica da experiência, que se tornou necessária ao sujeito.

Recebido em 15/12/2015. Aprovado em 18/1/2016. 


\title{
REFERÊNCIAS
}

BEATIE, Thomas. (2008) Labour of love: The Story of One Man's Extraordinary Pregnancy. Seal Press.

FERENCZI, Sandor. (1928/1982). "Le problème de la fin de l'analyse". Psychanalyse IV, Oeuvres complètes. Paris: Payot, p.43-52.

FREUD, Sigmund. (1937/1985). "L’analyse avec fin et l'analyse sans fin”. Résultats, Idées, Problèmes, II, Paris: PUF, p.266.

LAQUEUR, Thomas. (1992) La fabrique du sexe, Essai sur le corps et le genre en Occident. Paris: Gallimard.

RABINOVITCH, Solal. (2000) "Les négations constitutives du sujet", La forclusion. Ramonville: Scripta.

SCHAEFFER, Jacqueline. (1997) Le refus du féminin. Paris: PUF.

ZAPPERI, Roberto. (1979/1983) L'homme enceint, Homme, Femme et pouvoir. Paris: PUF.

\section{Obras consultadas}

LACAN, Jacques. (1974-1975). Réel et Symbolique et Imaginaire, Le Séminaire, Livre XXII. Dactylographie, Association Freudienne Internationale, Inédit. LACAN, Jacques (1972-1973/1975). Encore, Le séminaire, Livre XX. Paris: Seuil.

\author{
Vincent Bourseul \\ vincent.bourseul@gmail.com \\ Laurie Laufer \\ laurie.laufer@wanadoo.fr \\ Fabiana Campos Baptista \\ fabianabap@ig.com.br
}

